\title{
Prognostic Significance of Mean Platelet Volume to Lymphocyte Ratio in Patients with Metastatic Colon Cancer
}

\author{
Hayriye Şahinli1*, Esra Zeynelgil ${ }^{1}$, Özlem Doğan${ }^{1}$, Tülay Eren ${ }^{1}$, Gökşen İnanç İmamoğlu' \\ Mustafa Altınbaş ${ }^{1}$ and Sema Türker ${ }^{2}$ \\ ${ }^{1}$ Ankara Diskapi Yildırım Beyazit Training and Research Hospital, Medical Oncology, Turkey \\ ${ }^{2}$ Zonguldak Bülent Ecevit University Medical Faculty Hospital, Medical Oncology, Turkey
}

*Corresponding author: Hayriye Şahinli, Department of medical oncology, Ankara Dişkapı yildırim Beyazit Training and Research

Hospital, Ankara, Turkey

\section{ARTICLE INFO}

Received: 審 July 16, 2021

Published: 蔧 July 23, 2021

Citation: Hayriye Şahinli, Esra Zeynelgil, Özlem Doğan, Tülay Eren, Gökșen İnanç İmamoğlu, et al., Prognostic Significance of Mean Platelet Volume to Lymphocyte Ratio in Patients with Metastatic Colon Cancer. Biomed J Sci \& Tech Res 37(3)2021. BJSTR. MS.ID.006002.

Keywords: Colon Cancer; Platelet to Lymphocyte Ratio; Mean Platelet Volume

\section{ABSTRACT}

Background: The tumor microenvironment has become a very important in cancer progression. Immune cells in peripheral blood are essential elements of this environment. The prognostic significance of Mean Platelet Volume to Lymphocyte Ratio (MPVLR) in patients with metastatic colon cancer is unknown. Our aim is to investigate the prognostic significance of MPVLR.

Methods: A total of 116 patients with metastatic colon cancer were analyzed retrospectively between January 2014 and December 2020. The relationship between clinicopathological variables and MPVLR has been assessed with chi-square test. Log rank test and cox regression analysis were used for univariate and multivariate analysis. The best cut-off value of MPVLR for overall survival was determined by ROC curve analysis.

Results: The number of patients with MPVLR less than or equal to 5.4 was 39 (33.6\%), and those with MPVLR above 5.4 was 77 (66.4\%). Survival was worse in patients with MPVLR above 5.4 compared to patients below 5.4 (Hazard ratio (HR), 2.791; $95 \% \mathrm{Cl}, 1.511-5.515, \mathrm{P}=0.001$ ). The median survival could not be obtained in patients with MPVLR less than 5.4, while it was found as 22 months in patients with MPVLR above 5.4. There was no significant difference in progression-free survival between the two groups (HR, 1.181; 95\% Cl, 0.776-1.797, $\mathrm{p}=0.433$ ).

Conclusion: We found a shorter overall survival in patients with metastatic colon cancer with a high MPVLR value. This retrospective study is the first to investigate the prognostic significance of MPVLR for overall survival in patients with metastatic colon cancer.

\section{Introduction}

Colorectal cancer is the second most common cancer, the third most common cause of cancer death [1]. Approximately $25 \%$ of the patients have metastatic disease at the time of diagnosis, and about half of these patients die within the first 5 years [2]. Inflammation plays an important role in the development of cancer, tumor progression, angiogenesis, and cancer metastasis [3]. Infection, chronic irritation and inflammation are the underlying causes of the development of many types of cancer. Previous studies have shown that inflammatory biomarkers such as Neutrophil/ Lymphocyte Ratio (NLR), Plateret/Lymphocyte Ratio (PLR), Monocyte/Lymphocyte Ratio (MLR), Mean Platelet Volume (MPV), and C-reactive Protein (CRP) may be used as prognostic factors in gastrointestinal cancers $[4,5]$. Platelet activation is known to play an essential role in tumor growth and metastasis. Studies have 
shown that PLR is a negative prognostic marker in advanced cancer [6]. MPV is associated platelet activation and production as well as the mean platelet volume in the blood $[7,8]$. Studies revealed that MPV is closely related with many types of cancer such as colon, thyroid and, renal cell carcinoma [9-11].

Tumor Node Metastasis (TNM) staging system remains a prominent method in predicting prognosis and determining treatment options. However, the survival of patients even in the same stage varies. New biomarkers are required to determine the prognosis. Platelet, MPV and lymphocyte levels, which are among the most analyzed parameters in peripheral blood, are both costeffective and routinely usable inflammatory markers. In this study, we aimed to investigate the prognostic significance of MPVLR in patients with metastatic colon cancer.

\section{Methodology}

A total of one hundred sixteen patients, diagnosed as colon cancer with de novo metastatic disease or developed metastasis during follow-up, between January 2014 and December 2020, were retrospectively evaluated. Inclusion criteria for the study were patients over 18 years of age, histopathologically diagnosed with colon adenocarcinoma, and patients who developed metastases during diagnosis or during follow-up. Patients receiving antiinflammatory therapy, patients with hematological or autoimmune diseases, heart failure and hemodialysis patients were excluded from the study. Information obtained from patients' files and computer records are as follows: Age, gender, tumor localization (right colon vs. left colon), grade, number of chemotherapy steps, metastasis status at the time of diagnosis, blood hematological and biochemical markers, history of metastasectomy, KRAS, NRAS, BRAF mutation status, presence of liver metastases. Peripheral blood samples were taken from De nova metastatic patients before treatment. Peripheral blood samples were taken before any treatment when metastasis was detected in the patients who developed metastases during the follow-up.

Overall survival was determined as the length of time from metastatic diagnosis to death, or to the last follow-up date for survivors. Progression-free survival was accepted as the length of time from metastatic diagnosis to disease progression, or to the last follow-up date for patients without progression. All patients received biological agents such as bevacizumab, cetuximab or panitumumab depending on the mutation status. Peripheral venous blood samples were collected into sterile blood collection tubes containing Ethylenediaminetetraacetic Acid (EDTA) (5-7 ml). Mean platelet volume to lymphocyte ratio was estimated by dividing MPV (fL) by the number of lymphocytes (109/L). All statistical analyzes were performed using Statistical Package for the Social Sciences (SPSS) 20 (IBM Corporation, New York, NY) software.
The relationship between categorical variables was assessed by chi-square test. Categorical data were expressed as frequencies and percentages. The relationship between MPVLR and prognosis was evaluated using the cox analysis. Multivariant analysis was performed using the cox proportional hazards model. Hazard ratios (HR) were estimated from the cox regresyon analysis and were reported as relative risk with corresponding 95\% Confidence Intervals (Cls). Receiver Operating Characteristic (ROC) curve analysis was performed to estimate the best cut-off value of MPVLR for overall survival. The best cut-off point was expressed by using the Youden index (sensivity + specificity -1 ). A value of $\mathrm{P}<0.05$ was considered statistically significant.

\section{Results}

The clinicopathological characteristics of the patients were shown in Table 1. Forty-four (37.9\%) of 116 patients were female and $72(62.1 \%)$ were male. The median age of the patients was 65 (range 25-86) years. Median follow-up time was 21 months (0$105)$. The estimated 5 -year survival was $63 \%$. During the follow-up, $65(56 \%)$ of the patients died. Patients with confirmed mutation received targeted therapy as first line treatment. Mean platelet volume to lymphocyte ratio cut-off point for Overall Survival (OS) was estimated as 5.4 (AUC 0.800, 95\% Cl: 0.611-0.804, p=0.000) (Figure 1). Optimum cut off point for PLR was estimated as 171 (AUC 0.564, 95\% Cl: 0.458-0.670; $\mathrm{p}=0.237$ ). Specificity and sensitivity of MPVLR was $80 \%$ and 51\%, and of PLR $67 \%$ and 51\%, respectively. Median value of MPV estimated as cut off (median MPV $8 \mathrm{fL}$ ).

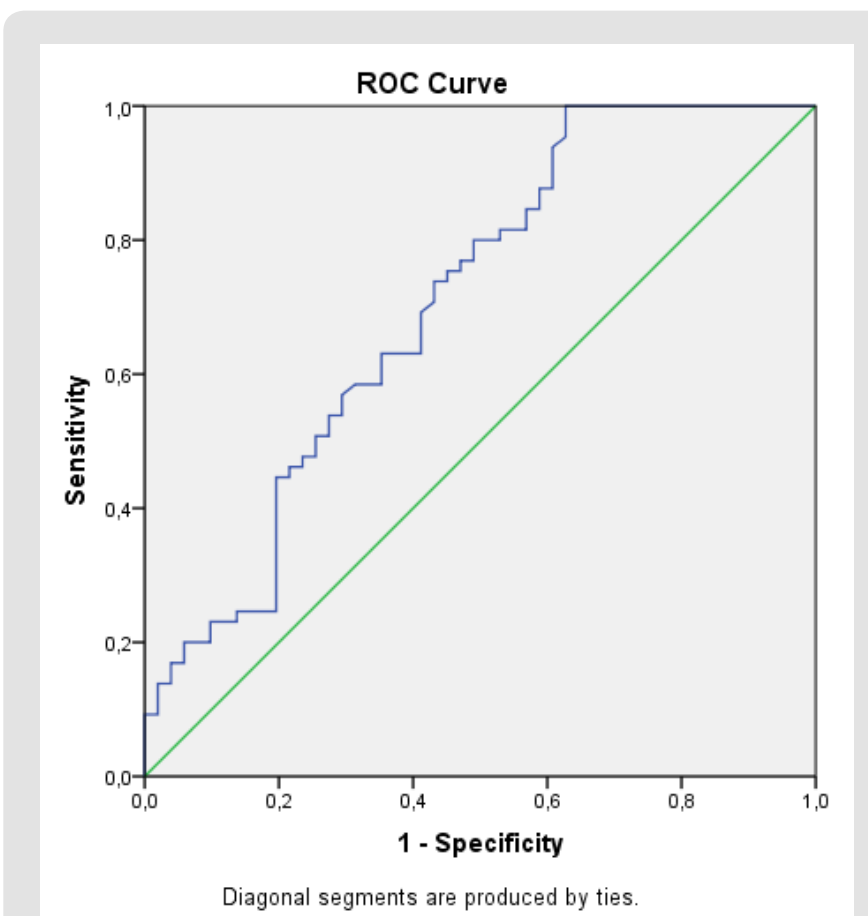

Figure 1: ROC curve analysis in patients with low and high MPVLR in terms of overall survival. 
Table 1: Clinicopathological characteristics of patients.

\begin{tabular}{|c|c|}
\hline Variables & n (\%) \\
\hline \multicolumn{2}{|l|}{ Age } \\
\hline$\leq 65$ & $74(63.8)$ \\
\hline$>65$ & $42(36.2)$ \\
\hline & $44(37.9)$ \\
\hline \multicolumn{2}{|l|}{ Female } \\
\hline Male & $72(62.1)$ \\
\hline \multicolumn{2}{|l|}{ ECOG } \\
\hline 0 & $71(61.2)$ \\
\hline$\geq 1$ & $41(31.3)$ \\
\hline Missing & $4(3.4)$ \\
\hline \multicolumn{2}{|l|}{ Stage } \\
\hline Stage 2 and 3 & $45(38.8)$ \\
\hline Stage 4 & $71(61.2)$ \\
\hline \multicolumn{2}{|l|}{ Grade } \\
\hline Grade 1 and 2 & $87(75)$ \\
\hline Grade3 & $29(25)$ \\
\hline \multicolumn{2}{|l|}{ Tumor site } \\
\hline Right sided & $23(19.8)$ \\
\hline Left sided & $93(80.2)$ \\
\hline \multicolumn{2}{|l|}{ KRAS } \\
\hline Wild & $54(46.6)$ \\
\hline Mutant & $51(44)$ \\
\hline Unknown & $11(9.5)$ \\
\hline \multicolumn{2}{|l|}{ Metastasectomy } \\
\hline No & $89(76.7)$ \\
\hline Yes & $27(23.3)$ \\
\hline \multicolumn{2}{|l|}{ Liver metastasis } \\
\hline Yes & $81(69.8)$ \\
\hline No & $35(30.2)$ \\
\hline \multicolumn{2}{|l|}{ Number of metastatic sites } \\
\hline$\leq 1$ & $46(39.7)$ \\
\hline$>1$ & $70(60.3)$ \\
\hline \multicolumn{2}{|l|}{ CEA } \\
\hline$\leq 5$ & $54(46.6)$ \\
\hline$>5$ & $62(53.4)$ \\
\hline \multicolumn{2}{|l|}{ MPV } \\
\hline$\leq 8.0$ & $60(51.7)$ \\
\hline$>8.0$ & $56(48.3)$ \\
\hline \multicolumn{2}{|l|}{ MPVLR } \\
\hline$\leq 5.4$ & $39(33.6)$ \\
\hline$>5.4$ & $77(66.6)$ \\
\hline \multicolumn{2}{|l|}{ PLR } \\
\hline$\leq 171$ & $47(40.5)$ \\
\hline$>171$ & $69(59.5)$ \\
\hline
\end{tabular}

ECOG: Eastern Cooperative Oncology Group Performance Status; CEA: Carcinoembryonic Antigen; MPV: Mean Platelet Volume; MPVLR: Mean Platelet Volume to Lymphocyte ratio; PLR: Platelet to Lymphocyte ratio
There was no significant relationship between age, gender, grade, de novo metastasis, number of received chemotherapy lines, tumor location, and MPVLR. A significant relationship was found between MPVLR and PLR ( $\mathrm{p}<0.001)$, and metastasectomy $(\mathrm{p}=0.006)$ (Table 2). Mean platelet volume to lymphocyte ratio was categorized into two groups according to cut off point. There were 39 and 77 patients in MPVLR below 5.4 and above 5.4 groups, respectively. Death occurred in 13 out of 39 patients with MPVLR level below 5.4 while 52 out of 77 patients died in the other group. Survival was worse in patients with MPVLR above 5.4 (HR: 2.149, $95 \mathrm{Cl}$ : 1.085-4.255, p=0.001). Median survival was not available in patients with MPVLR less than 5.4, while it was 22 months in patients with MPVLR above 5.4 (Figure 2). Univariate analysis revealed that metastasectomy $(\mathrm{p}=0.009)$, number of chemotherapy lines $(p=0.026)$, PLR $(p=0.009)$ and MPVLR $(p=0.001)$ had significant effect on overall survival. There was no significant effect of age (0.101), gender (0.428), grade (0.546), presence of liver metastases (0.627), de novo metastasis ( $\mathrm{p}=0.220)$, KRAS mutation status (0.685), MPV (0.120), and CEA (0.131) on overall survival. Multivariate cox regression analysis showed that the effects of metastasectomy (HR: 0.446, 95\% Cl: 0.226-0.883, p=0.020), number of chemotherapy lines (HR: 0.497, 95\% Cl: 0.297-0.833, $\mathrm{p}=0.008$ ) and MPVLR (HR: 2.149, 95\% Cl 1.085-4.255, p=0.031) on overall survival continued (Table 3 ). Univariate analysis showed no significant effect of age $(\mathrm{p}=0.542)$, gender $(\mathrm{p}=0.712)$, de novo metastasis $(p=0.133)$, KRAS mutation status $(p=0.251)$, and PLR $(p=0.08)$ on Progression Free Survival (PFS). Metastasectomy was found to have significant effect on PFS ( $p=0.049)$. There was no significant difference in PFS between patients with MPVLR below and above 5.4 ( $\mathrm{P}=0.422$, HR: $1.181 \mathrm{Cl}$ : 0.776-1.797).

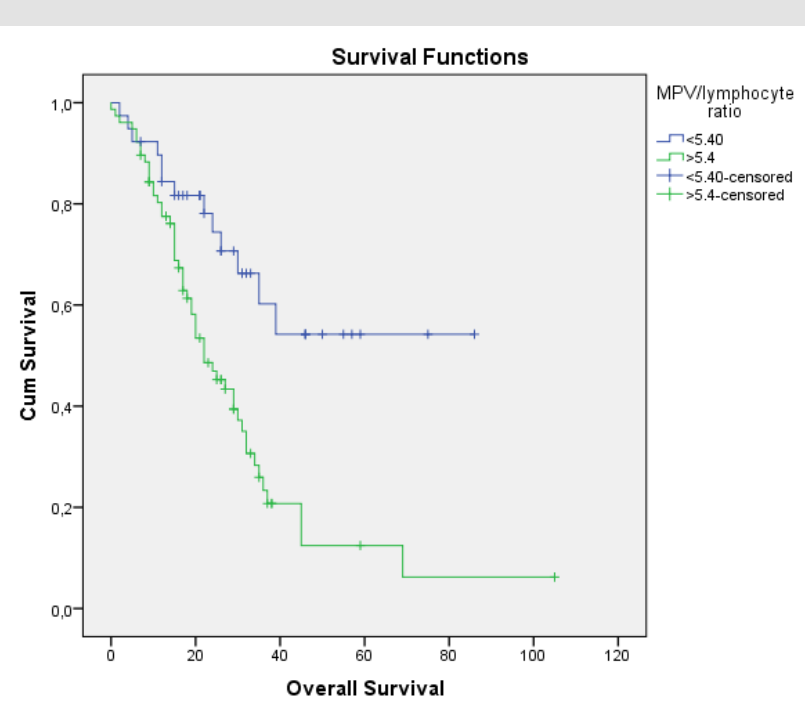

Figure 2: Kaplan-Meier of survival based on the MPVLR in metastatic colon cancer patients. 
Table 2: Relationship between clinicopathological characteristics and MPVLR.

\begin{tabular}{|c|c|c|c|}
\hline Variables & Low MPVLR, n (\%) & High MPVLR n (\%) & P-value \\
\hline \multicolumn{4}{|l|}{ Age } \\
\hline$\leq 65$ & $25(64.1)$ & $49(63.9)$ & 0.961 \\
\hline$>65$ & $14(35.9)$ & $28(36.4)$ & \\
\hline \multicolumn{4}{|l|}{ Gender } \\
\hline Female & $17(43.6)$ & $27(35.1)$ & 0.371 \\
\hline Male & $22(56.4)$ & $50(64.9)$ & \\
\hline \multicolumn{4}{|l|}{ Grade } \\
\hline 1 and 2 & $29(74.4)$ & $58(75.3)$ & 0.910 \\
\hline 3 & $10(25.6)$ & $19(24.7)$ & \\
\hline \multicolumn{4}{|c|}{ Denovo metastasis } \\
\hline Yes & $24(61.5)$ & $47(61)$ & 0.958 \\
\hline No & $15(38.5)$ & $30(39)$ & \\
\hline \multicolumn{4}{|c|}{ Metastasectomy } \\
\hline No & $24(61.5)$ & $65(84.4)$ & 0.006 \\
\hline Yes & $15(38.5)$ & $12(15.6)$ & \\
\hline \multicolumn{4}{|c|}{ Number of chemotherapy cycle } \\
\hline$\leq 1$ & $15(38.5)$ & $31(40.3)$ & 0.852 \\
\hline$>1$ & $24(61.5)$ & $46(59.7)$ & \\
\hline \multicolumn{4}{|l|}{ Tumor site } \\
\hline Right sided & $10(25.6)$ & $13(16.9)$ & 0.264 \\
\hline Leftsided & $29(74.4)$ & $64(83.1)$ & \\
\hline \multicolumn{4}{|l|}{ MPV } \\
\hline$\leq 8$ & $22(56.4)$ & $38(49.4)$ & 0.556 \\
\hline$>8$ & $17(43.6)$ & $39(50.6)$ & \\
\hline \multicolumn{4}{|l|}{ PLR } \\
\hline$\leq 171$ & $28(71.8)$ & $19(24.7)$ & 0.00 \\
\hline$>171$ & $11(28.2)$ & $58(75.3)$ & \\
\hline
\end{tabular}

MPV: Mean Platelet Volume; PLR: Platelet to Lymphocyte ratio; MPVLR: Mean Platelet Volume to Lymphocyte ratio

Table 3: Univariate and multivariate analyzes of clinicopathologic variables in terms of overall survival.

\begin{tabular}{|c|c|c|}
\hline Variable & Overall survival Univariate analysis P value (log-rank) & Multivariate analysis P value HR Cl \% \\
\hline Age & 0.101 & \\
$\leq 65$ & $1.510(0.923-2.472)$ & \\
$>65$ & 0.428 & \\
\hline Gender & $0.817(0.495-1.348)$ & \\
Male & 0.546 & \\
Female & $0.829(0.451-1.523)$ & \\
\hline Grade & 0.131 & \\
Grade1-2 & $1.472(0.892-2.431)$ & \\
Grade3 & \\
\hline CEA & \\
\hline 5 & & \\
\hline
\end{tabular}




\begin{tabular}{|c|c|c|}
\hline $\begin{array}{c}\text { De novo metastasis } \\
\text { Yes } \\
\text { No }\end{array}$ & $\begin{array}{c}0.220 \\
1.392(0.820-2.363)\end{array}$ & \\
\hline $\begin{array}{l}\text { Liver metastasis } \\
\qquad \begin{array}{l}\text { Yes } \\
\text { No }\end{array}\end{array}$ & $\begin{array}{c}0.627 \\
1.151(0.652-2.033)\end{array}$ & \\
\hline $\begin{array}{c}\text { Metastasectomy } \\
\text { Yes } \\
\text { No }\end{array}$ & $\begin{array}{c}0.009 \\
0.410(0.211-0.797)\end{array}$ & $\begin{array}{c}0.020 \\
0.446(0.226-0.883))\end{array}$ \\
\hline $\begin{array}{l}\text { KRAS mutation } \\
\text { Mutant } \\
\text { Wild } \\
\text { Unknow }\end{array}$ & $\begin{array}{c}0.685 \\
1.085(0.731-1.613)\end{array}$ & \\
\hline $\begin{array}{l}\text { Line numbers of chemotherapy } \\
\qquad \begin{array}{l}\leq \text { First line } \\
>\text { First line }\end{array}\end{array}$ & $\begin{array}{c}0.026 \\
0.563(0.340-0.933)\end{array}$ & $\begin{array}{c}0.008 \\
0.497(0.297-0.833)\end{array}$ \\
\hline $\begin{array}{l}\text { MPV } \\
\leq 8 \\
>8\end{array}$ & $\begin{array}{c}0.120 \\
1.475(0.904-2.406)\end{array}$ & \\
\hline $\begin{array}{l}\text { PLR } \\
\leq 171 \\
>171\end{array}$ & $\begin{array}{c}0.009 \\
2.011(1.193-3.389)\end{array}$ & $\begin{array}{c}0.372 \\
1.303(0.729-2.328)\end{array}$ \\
\hline $\begin{array}{l}\text { MPVLR } \\
\leq 5.40 \\
>5.40\end{array}$ & $\begin{array}{c}0.001 \\
2.791(1.511-5.155)\end{array}$ & $\begin{array}{c}0.028 \\
2.149(1.085-4.255)\end{array}$ \\
\hline
\end{tabular}

MPV: Mean Platelet Volume; PLR: Platelet to Lymphocyte ratio; MPVLR: Mean Platelet Volume to Lymphocyte ratio.

\section{Discussion}

In our study, survival was found to be shorter in patients with high MPVLR, and high MPVLR was determined as poor prognostic factor in metastatic colon cancer. This study was the first to investigate the prognostic effect of MPVLR on metastatic colon cancer. The relationship between inflammation and cancer was defined by Rudolf Virchow in the $19^{\text {th }}$ century [12]. Lymphocytes constitute the main component of the immune system. Tumor-Infiltrating Lymphocytes (TILs), constitute one of the most important effector mechanisms of anti-tumor immunity [13]. Tumor cells are surrounded by immune cells, especially lymphocytes. Lymphocytes play an important role in anti-tumor immunity by inducing apoptosis and preventing the migration and proliferation of tumor cells [14-16]. Lymphopenia was determined to be associated with poor prognosis in many types of cancer [16-19]. Platelets play an important role in hemostasis and thrombosis. In addition, platelets contribute to the growth, dissemination, and angiogenesis process of tumor cells. Plateletderived growth factor, mainly secreted from platelets, and tissue growth factor also leads to tumor growth [20,21]. Proinflammatory cytokines released by cancer cells increase platelet count through megakaryocyte proliferation [22]. Considering the relationship between platelet and cancer, platelet-based markers can be used to determine the prognosis of colon cancer. Mean platelet volume is used for measurement of platelet diameter indicating platelet activation. Large platelets are more reactive than small ones and are more likely to cluster to induce thrombosis. The function of platelets often depends on their size. Mean platelet volume better indicates platelet activation than platelet count [23]. Furthermore, MPV has been shown to have an important prognostic role in many malignancies such as gastrointestinal tumors, colorectal cancer, and lung cancer $[24,25]$. High PLR has been known from previous studies to be a poor prognostic factor in cancer [6]. It was supposed that use of MPV, a better indicator of platelet activation, instead of platelet count in PLR would be more indicative in determining prognosis.

This study is the first to investigate the effect of MPVLR on survival in metastatic colon cancer. In our study, the cut-off point 
of MPVLR for overall survival was estimated by ROC curve analysis. We determined cut off point for MPVLR as 5.4. High MPVLR was found to be a poor prognostic factor in patients with metastatic colon cancer. Survival was shorter in patients with high MPVLR. The limitations of our study were its retrospective design, and the fact that although undergoing bevacizumab, cetuximab, or panitumumab regimen according to KRAS and NRAS status, patients did not receive the same treatments due to not having the same mutation. As a result, MPVLR analysis before treatment, can be used in patients with metastatic colon cancer as a cheap and easily available prognostic marker.

\section{Ethical Approval}

This study was approved by Ankara Dişkapi Yildirim Beyazit Training and Research Hospital Medical Ethics Committee (Approval No: 73/08).

\section{References}

1. Ferlay J, Soerjomataram I, Dikshit R, Eser S, Mathers C, et al. (2015) Cancer incidence and mortality worldwide: sources, methods and major patterns in GLOBOCAN 2012. Int J Cancer 136 (5): E359-E386.

2. Aranda E, Aparicio J, Alonso V, Garcia-Albeniz X, Garcia-Alfonso P, et al. (2015) SEOM clinical guidelines for diagnosis and treatment of metastatic colorectal cancer 2015. Clin Transl Oncol 17(12): 972-981.

3. Zhang M, Huang XZ, Song YX, Gao P, Sun JX, et al. (2017) High plateletto-lymphocyte ratio predicts poor prognosis and clinicopathological characteristics in patients with breast cancer: a meta-analysis. Biomed Res Int. 2017: 9503025.

4. Zhang J, Zhang HY, Li J, Shao XY, Zhang CX (2017) The elevated NLR, PLR and PLT may predict the prognosis of patients with colorectal cancer: a systematic review and meta-analysis. Oncotarget 8(40): 68837-68846.

5. Bardash Y, Olson C, Herman W, Khaymovich J, Costantino P, et al. (2019) Platelet-lymphocyte ratio as a predictor of prognosis in head and neck cancer: a systematic review and meta-analysis. Oncol Res Treat 42(12): 665-677.

6. Li B, Zhou P, Liu Y, Wei H, Yang X, et al. (2018) Platelet-to-lymphocyte ratio in advanced Cancer: Review and meta-analysis. Clin Chim Acta 483: 48-56.

7. Chang J, Lin G, Ye M, Tong D, Zhao J, et al. (2019) Decreased mean platelet volume predicts poor prognosis in metastatic colorectal cancer patients treated with first-line chemotherapy: results from mCRC biomarker study. BMC Cancer 19(1): 15.

8. Wang JM, Wang Y, Huang YQ Wang H, Zhu J, et al. (2019) Prognostic values of platelet-associated indicators in resectable cervical cancer. Dose Response 17(3): 1559325819874199.

9. Li JY, Li Y, Jiang Z, Wang RT, Wang XS (2014) Elevated mean platelet volume is associated with presence of colon cancer. Asian Pac J Cancer Prev 15(23): 10501-10504.

10. Yu YJ, Li N, Yun ZY, Niu Y, Xu JJ, et al. (2017) Preoperative mean platelet volume and platelet distribution associated with thyroid cancer. Neoplasma 64(4): 594-598.
11. Yun ZY, Zhang X, Liu ZP, Liu T, Wang RT, et al. (2017) Association of decreased mean platelet volume with renal cell carcinoma. Int J Clin Oncol 22(6): 1076-1080.

12. Balkwill F, Mantovani A (2001) Inflammation and cancer: back to Virchow? Lancet 357(9255): 539-545.

13. Zhao J, Huang W, Wu Y, Luo Y, Wu B, et al. (2020) Prognostic role of pretreatment blood lymphocyte count in patients with solid tumors: a systematic review and meta-analysis. Cancer Cell Int 20: 15.

14. Mantovani A, Allavena P, Sica A, Balkwill F (2008) Cancer-related inflammation. Nature 454(7203): 436-444.

15. Gooden MJ, de Bock GH, Leffers N, Daemen T, Nijman HW (2011) The prognostic influence of tumour-infiltrating lymphocytes in cancer: a systematic review with meta-analysis. Br J Cancer 105(1): 93-103.

16. Ray-Coquard I, Cropet C, Van Glabbeke M, Sebban C, Le Cesne A, et al. (2009) Lymphopenia as a prognostic factor for overall survival in advanced carcinomas, sarcomas, and lymphomas. Cancer Res 69(13): 5383-5391.

17. Wu ES, Oduyebo T, Cobb LP, Cholakian D, Kong X, et al. (2016) Lymphopenia and its association with survival in patients with locally advanced cervical cancer. Gynecol Oncol 140(1): 76-82.

18. Saroha S, Uzzo RG, Plimack ER, Ruth K, Al-Saleem T (2013) Lymphopenia is an independent predictor of inferior outcome in clear cell renal carcinoma. J Urol 189(2): 454-461.

19. Joseph N, Dovedi SJ, Thompson C, Lyons J, Kennedy J, et al. (2016) Pretreatment lymphocytopaenia is an adverse prognostic biomarker in muscle-invasive and advanced bladder cancer. Ann Oncol 27(2): 294299.

20. Zou ZY, Liu HL, Ning N, Li SY, Du XH (2016) Clinical significance of preoperative neutrophil lymphocyte ratio and platelet lymphocyte ratio as prognostic factors for patients with colorectal cancer. Oncol Lett. 11(3): 2241-2248.

21. Yodying H, Matsuda A, Miyashita M, Matsumoto S, Sakurazawa N, et al. (2016) Prognostic significance of neutrophil-to-lymphocyte ratio and platelet-to-lymphocyte ratio in oncologic outcomes of esophageal cancer: a systematic review and meta-analysis. Ann Surg Oncol 23(2): 646-654.

22. Shen XM, Xia YY, Lian L, Zhou C, Li XL, et al. (2016) Mean platelet volume provides beneficial diagnostic and prognostic information for patients with resectable gastric cancer. Oncol Lett 12(4): 2501-2506.

23. Kurtul A, Acikgoz SK (2017) Usefulness of mean platelet volume-tolymphocyte ratio for predicting angiographic no-reflow and short-term prognosis after primary percutaneous coronary intervention in patients with st-segment elevation myocardial infarction. Am J Cardiol 120(4): 534-541.

24. Li N, Lv XH, Wang X, Wang RT, Huang YX (2019) Preoperative mean platelet volume predicts survival in breast cancer patients with type 2 diabetes. Breast Cancer 26(6): 712-718.

25. Wang X, Cui MM, Xu Y, Liu L, Niu Y, et al. (2017) Decreased mean platelet volume predicts poor prognosis in invasive bladder cancer. Oncotarget 8(40): 68115-68122. 
ISSN: 2574-1241

DOI: 10.26717/BJSTR.2021.37.006002

Hayriye Şahinli. Biomed J Sci \& Tech Res

(c) (P) This work is licensed under Creative

Submission Link: https://biomedres.us/submit-manuscript.php

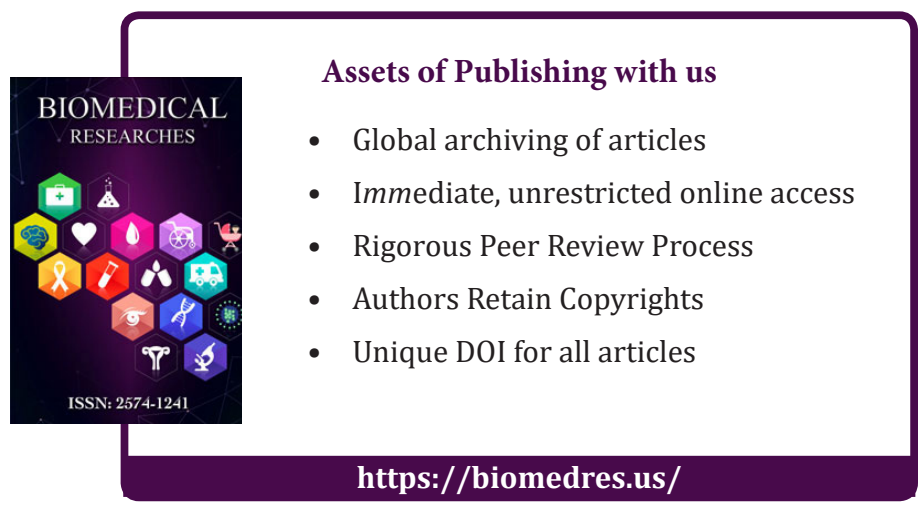

